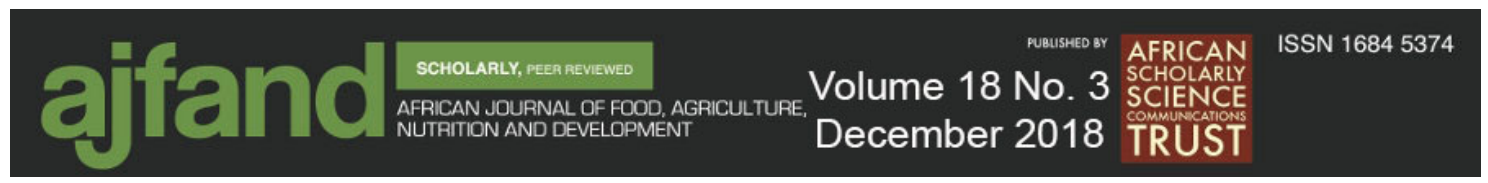

Afr. J. Food Agric. Nutr. Dev. 2018; 18(3): 13842-13860

DOI: 10.18697/ajfand.83.17000

\title{
FACTORS ASSOCIATED WITH STUNTING \\ IN DODOMA REGION, TANZANIA
}

\author{
Makori $\mathbf{N}^{1^{*}}$, Kassim $\mathrm{N}^{1}$, Kinabo $\mathrm{J}^{2}$ and A Matemu ${ }^{1}$
}

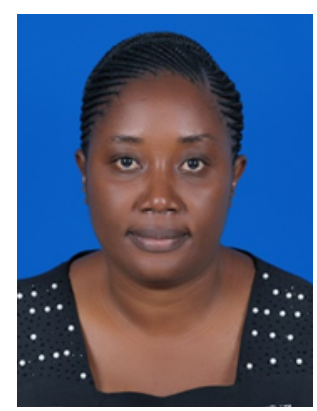

Nyabasi Makori

*Corresponding author email: nmakori01@gmail.com

${ }^{1}$ Department of Food Biotechnology and Nutritional Sciences, School of Life Sciences and Bioengineering, Nelson Mandela African Institution of Science and Technology, P. O. Box 447, Arusha, Tanzania

${ }^{2}$ Department of Food Technology, Nutrition and Consumer Sciences, Sokoine University of Agriculture, P. O. Box 3006, Morogoro, Tanzania 


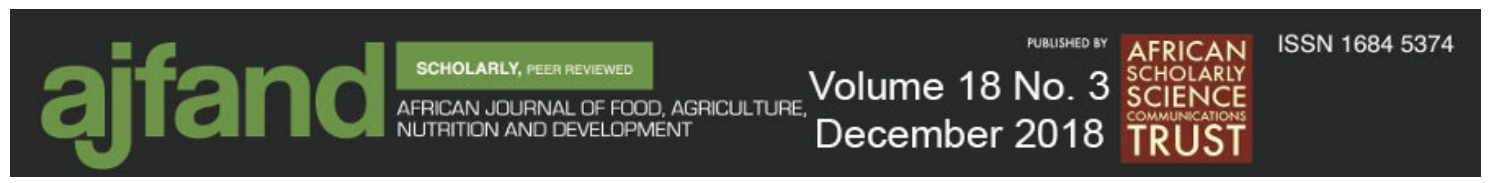

\section{ABSTRACT}

Child undernutrition is a major public health concern, claiming the lives of numerous children below five years of age in the developing world. The objective of this study was to assess the factors associated with stunting of children of age 6-23 months in Dodoma Municipality and Chamwino District in Dodoma region. Dodoma region located in the central zone of Tanzania was chosen for this study because of its high prevalence $(56 \%)$ of stunting among children under five years of age. A systematic random sampling technique was used to choose wards, villages, and households that had children aged 6 23 months, resulting in 394 households participating in this cross-sectional study. A standardized questionnaire was used to collect socio-demographic information and infant feeding practices. Anthropometric measurements were taken as per WHO standard procedures. A repeated 24-hour dietary recall was used to assess food intake among the study population. Multivariate logistic regression using backward stepwise selection method was used to obtain independent factors of stunting. The overall prevalence of stunting was 40.4\% (95\% CI; 29.8; 50.9), Chamwino District had a higher prevalence of stunting (44.3\%) compared to Dodoma municipality (26.3\%). Multivariate logistic regression analysis showed that, age of introduction of complementary food [AOR = 13.3; (95\% CI: 2.6 - 67.6)], maternal education [AOR $=5.5$; (95\% CI: $1.0-9.8)$ ], residence in Chamwino District [AOR $=3.2 ;(95 \% \mathrm{CI}: 1.3-5.9)]$ were factors associated with stunting. About half of the study population (49\%) was introduced to complementary foods early, the median age was four months instead of 6 months as recommended by WHO. Infant's diet was mainly cereal-based, other foods such as animal food source, fruits, and dairy products were consumed by $18 \%, 11 \%$ and $7.1 \%$ of children respectively. The dietary pattern of infants was not diversified as $47.7 \%$ of infants scored 1 to 3 points out of 12 points categorized as low dietary diversity. Failure to attain normal growth pattern is the most prevalent form of undernutrition in childhood. Associated factors are many, diverse and interrelated. The present study identified maternal education, early introduction of complementary foods and being a resident of Chamwino District as factors to be associated with stunting. Prioritization of identified factors serves as a highlight for better planning of nutrition intervention programs that intend to promote child growth.

Key words: Stunting, nutrition status, $6-23$ months, dietary diversity and complementary food 


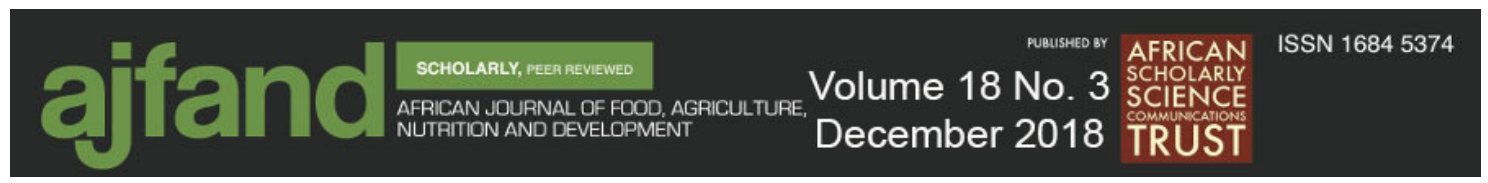

\section{INTRODUCTION}

Undernutrition continues to threaten growth, survival, and development of infants and young children in developing countries [1]. Globally, 165 million children of age below 5 years have been reported to be stunted [2]. In addition, $45 \%$ of death among children in this age group is associated with undernutrition [2]. The prevalence of undernutrition is high between the ages of $6-23$ months. This is a period of rapid growth and high nutrient requirements; therefore, it is a critical period for growth faltering and nutritional deficiencies if the nutritional needs of children are not attained [3]. Stunting in childhood is caused by many factors including diseases, food insecurity, lack of access to health services, inadequate maternal/child caring practices and also inadequate dietary intake which is an outcome of prolonged deprivation of essential nutrients to meet demands for growth. Stunting has adverse health consequences that may extend to adulthood [4]. Poor cognitive ability and educational attainment have been confirmed in longitudinal studies as being the consequence of stunting in children, which tend to impart extended detrimental effects in adulthood [5-10].

In Tanzania, stunting is still a public health concern affecting $34 \%$ of children of age below five years [11]. Reports of the Tanzania Demographic Health Survey (TDHS) have shown trends of child stunting, in 1996 and 1999 the prevalence of stunting was $43.4 \%$ and $43.8 \%$ respectively [12,13]. In 2010 and $2015 / 2016,42 \%$ and $34 \%$ of children were reported to be stunted respectively, the prevalence has declined by $9.3 \%$ for the past 20 years $[11,14]$. Dodoma region is one of the regions in Tanzania having a high prevalence of stunting. In 2010 about $56 \%$ of children were reported to be stunted and in 2015 , the prevalence had been reduced to $36 \%[11,14]$. The decline of the prevalence of stunting might be contributed by the establishment of clear coordination of nutritional activities and increased allocation of human and financial resources on nutritional related intervention programs in the country.

The prevailing causes of stunting are multifactorial ranging from infections (parasitic, HIV, helminths), insufficient intake and poor absorption of nutrients, sub-optimal breastfeeding practices, poor child-care practices, and poverty $[15,16]$. The need to investigate factors contributing to undernutrition among children is crucial especially in breaking the intergenerational cycle of malnutrition. However, factors associated with stunting have been studied and observed to vary from one area to another based on geographical location, ethnicity, and cultural practices. Therefore, this study assessed the independent factors associated with stunting among children of age 6 to 23 months in Dodoma municipality and Chamwino District of Dodoma region for development and strengthening appropriate nutritional strategies and programs intended to promote child growth.

\section{METHODOLOGY}

\section{Study population}

A total of 394 children within the age range of 6 to 23 months participated in the study. In each household, only one child was assessed. Criteria for the selection of respondents 


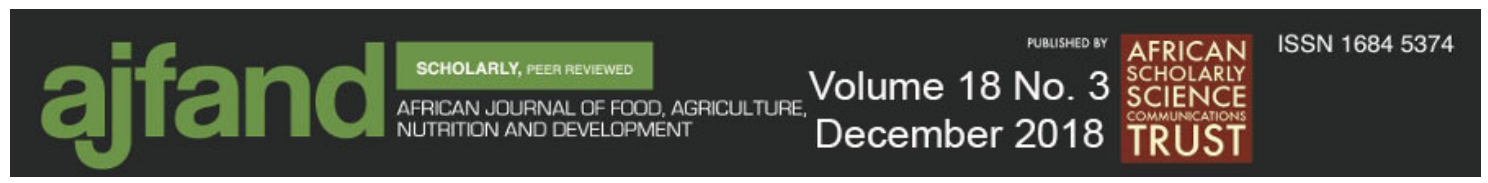

were based on age and area of residence (Chamwino and Dodoma Municipality). Twins, disabled and seriously sick children were not included in the study.

\section{Study Design, Sample Size, and Sampling Procedure}

A cross-sectional study conducted in Dodoma region intended to assess factors associated with stunting among infants and young children. Dodoma region was purposively selected for being a study area because it was ranking the first region in the country with the highest prevalence (56\%) of stunting in children of under five years of age [13]. The sample size for this study was determined by using the formula for crosssectional studies by Varkevisser et al. [17] whereby the minimum sample size was 378 subjects, however, a total of 394 children (204 male and 190 female) were recruited in the study. Simple random sampling technique by using random numbers was used to select two Districts out of seven Districts in the region, Dodoma Municipality and Chamwino district were picked to be study areas. Sample size among the two districts was distributed by using the prevalence of stunting of the respective district, therefore, a total of 175 ( 82 female and 93 male) children were recruited in Dodoma Municipality and 219 (108 female and 111 male) children in Chamwino District. A systematic random sampling technique was used to select ward and villages to participate in this study, a list obtained from ward executive officers was used to select respective wards and villages involved in this study whereby after every $\mathrm{n}^{\text {th }}$ interval ward and the village was selected from the list. Therefore, three wards of Dodoma Municipality (Makole, Chigongwe, and Mahoma Makulu) and four wards of Chamwino District (Mvumi Mission, Mlowa, Ikowa and Manchali) were chosen to be study areas. A total of 14 villages were covered in this study and in each selected ward, two villages were randomly sampled. A list of all households that were having children of age between 6 and 23 months was obtained from the respective village offices, systematic randomly sampling was used to select households recruited in this study.

\section{Household Interviews and Anthropometric Measurement}

A structured questionnaire was pre-tested and refined before it was administered to mothers/caregivers at the households to collect socio-demographic data. Information on food consumption was collected twice in two non-consecutive visits using a 24-hour dietary recall method. The days of visits covered one day for weekdays and the second day for weekends. During the interview, each parent/guardian was asked to recall all types of foods and beverage consumed by their infants in the past 24-hours. Mothers were asked to provide detailed information about applied food preparation methods and type of ingredients used. Amount of food reported to be consumed in the 24-hour dietary recall was estimated by using household utensils such as cups, bowls, and spoons. The estimated portion was weighed using a kitchen scale (CAMRY, model EK3131) and the weight was recorded accordingly. Dietary Diversity Scores (DDS) were estimated by using dietary information collected from the 24-hour dietary recall. Dietary diversity of the studied population was measured using a scale of twelve food groups as per the Food and Agriculture Organization (FAO) to measure DDS [18]. Assessment of dietary diversity was done based on the number of food groups consumed over the past 24 hours. These food groups included: cereals-based foods, roots and tubers, legumes, fruits, vegetables, fish, eggs, meat and milk product, milk and milk products, sugar, oil and fats, spices and condiments (Table 2). To each food group consumed over a reference period, 


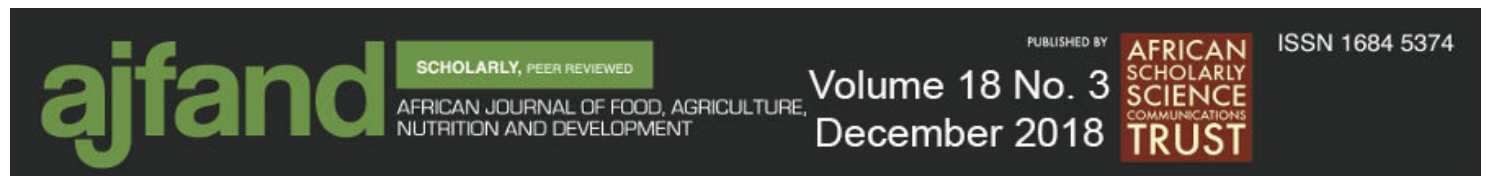

a point was given, and then, the DDS was calculated as a summation of all points scored. Dietary diversity categories were derived from 12 points as follows: low dietary diversity $1-3$ points, medium dietary diversity $4-6$ points and high dietary diversity $7-12$ points. The diversity of the diet was judged based on the scores.

Anthropometry measurement was performed according to the World Health Organization (WHO) guideline [19]. Recumbent length of a child was measured using a length board (210; Seca, Hamburg, Germany) to the nearest $0.1 \mathrm{~cm}$. A combined weight of both mother and a child was measured using a standard weighing scale (HD-386-BK; Tanita, Tokyo, Japan) to the nearest $0.1 \mathrm{~kg}$. The weight of a child was then recorded as a result of subtracting mother's weight from a combined weight of the mother and child.

\section{Ethical Clearance}

Ethical approval for conducting this study was obtained from the National Health Research Ethics Sub-Committee (NatHREC) of the National Institute of Medical Research (NIMR) of Tanzania, reference number NIMR/HQ/R.8a/Vol.IX/1973. The parent or caretaker of each individual child signed an informed consent. Confidentiality was observed throughout the study.

\section{Statistical analysis}

Data and responses from questionnaires were coded and double entered into an Epidata version 3.1 by two independent people. Emergency Nutrition Assessment (ENA) for SMART version 2011 was used to analyze data obtained from the anthropometric measurement. Z-scores and the prevalence of stunting were calculated according to the child growth standards of the WHO [19]. Data from the household survey were then exported to SPSS for Windows software (IBM version 21) for analysis. Difference between groups was compared using Pearson Chi-square statistical test whereas Crude Odds Ratio (COR) and Adjusted Odds Ratio (AOR) with 95\% Confidence Intervals (CI) were used to assess the strength of association. Differences were considered statistically significant if $p \leq 0.05$. Variables that were significant in the univariate analysis were analyzed using multivariate analysis. Multivariate logistic regression modeling was used to assess factors of stunting. The procedure used was backward stepwise selection with removal testing that was based on the probability of the likelihood ratio statistic. The significance level of a likelihood ratio statistic was compared to a cut-off value of $p \leq 0$. 1. Seven variables (Table 3 ) were considered in the initial model, only 3 variables were considered significant based on the $p$ value for likelihood ratio and nutritional epidemiological importance. The district was not considered in the univariate analysis, rather in the multivariate model because it was an important exposure.

\section{RESULTS}

\section{Demographic characteristics}

A total of 394 children were involved in the study, $204(51.8 \%)$ were males and 190 females $(48.2 \%)$. The mean age of children was $13.7 \pm 5.3$ months and that of mothers was $28.2 \pm 7.3$ years respectively. Table 1 summarizes the social demographic information of the studied children and their mothers/caregivers. The majority $(82.3 \%)$ of the households were living below the poverty line as they spend less than 1 USD per 


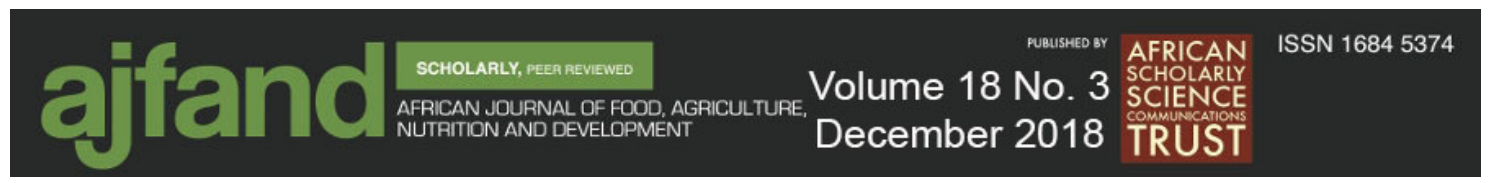

day. The number of household members ranged between 2 and 20 people, with the mean of 5 people per household.

\section{Feeding Practices and Dietary Pattern}

Results indicated that $91 \%(n=357)$ of children were still breastfeeding, $49 \%$ of infants were introduced to complementary foods before the age of 6 months. The median age of initiation of complementary food was four months. Factors associated with early introduction of complementary food include; mother's own perception that her infant was not satisfied with breast milk, mothers felt that they did not have enough milk, cases of crying baby, demand for mothers to resume their work, and some mothers wanted their infants to get used to complementary feeding before recommended age. Additionally, the number of meals given to infants per day ranged between one and five, with a mode of three meals per day. Feeding frequency differed among age groups whereby for infants who were less than one year, $1.4 \%$ were fed four times, $54 \%$ three times, $43 \%$ twice and $1.6 \%$ once per day. Those infants who were above one year, $2.8 \%$ were fed fifth times, $42 \%$ fourth times, $46.2 \%$ three times and $9 \%$ twice per day. Furthermore, the study found that $65 \%$ of mothers do not know exactly how many times a child is supposed to be fed in a day.

The typical dietary pattern of children was characterized by high consumption of cerealbased products such as maize or millet along with vegetables. The overall mean for dietary diversity was $3.6 \pm 1.0$ with a range of $2-8$ points. Based on dietary diversity categorization, $51.5 \%$ of children were categorized as having medium dietary diversity score ( $4-6$ points), $47.7 \%$ on low dietary diversity score ( $1-3$ points) and $0.8 \%$ on high dietary diversity score ( $7-12$ points). The distribution of DDS for Chamwino and Dodoma Municipality is shown in Figure 1, Chamwino District had a higher proportion of children who had low DDS (50.5\%) compared to Dodoma Municipality (40\%). A high proportion $(58.3 \%)$ of children in Dodoma Municipality had medium DDS. Food groups consumed by infants and young children are presented in Table 2 . Cereals were the most dominant food and were consumed by $100 \%$ of children. Animal source foods were the least consumed (18\%) except for breast milk. Other foods such as fruits and dairy products were consumed by a small proportion of children by $11 \%$ and $7.1 \%$, respectively. 

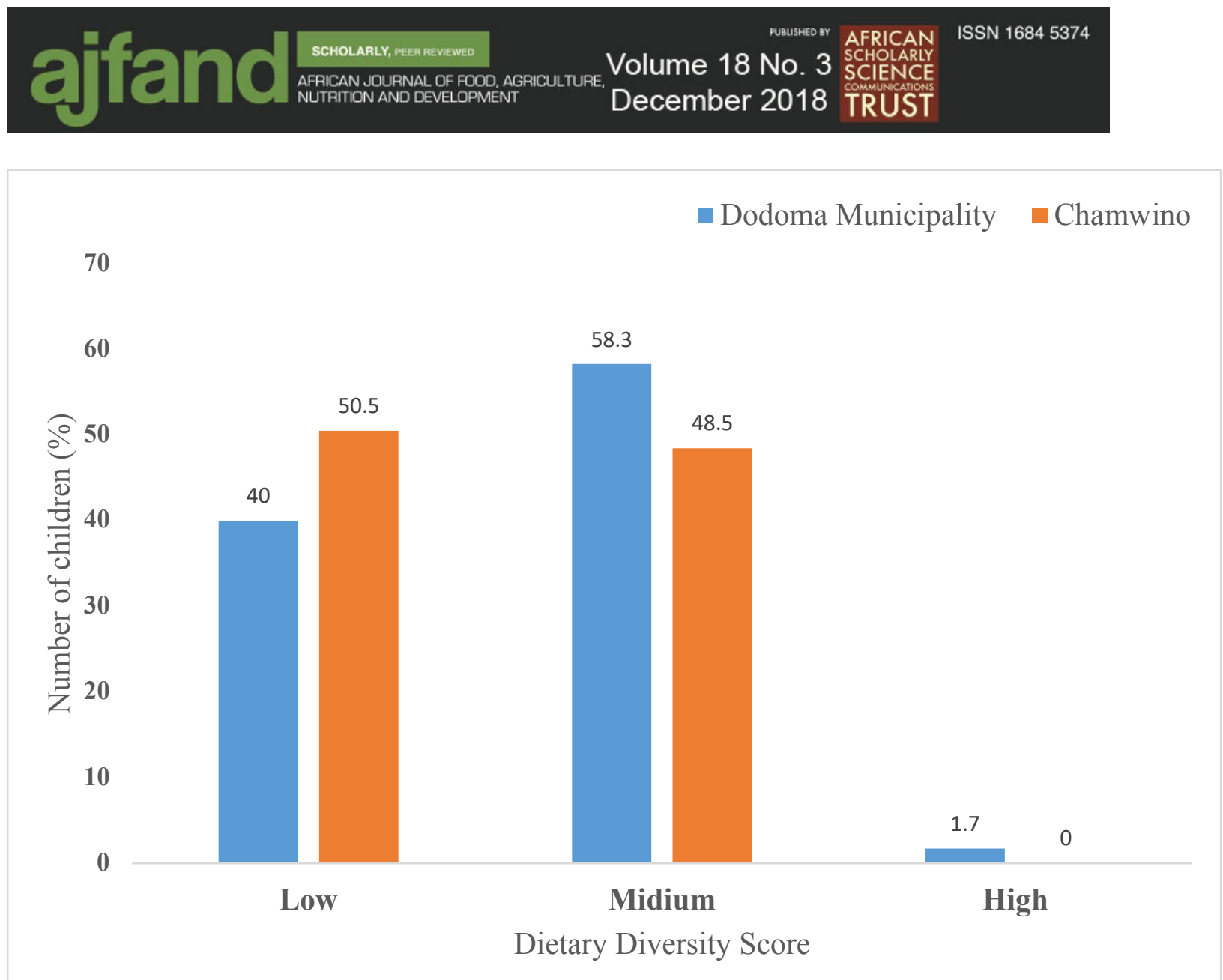

Figure 1: Dietary Diversity Scores of Dodoma Municipality and Chamwino District

\section{Nutritional Status}

The distribution of height-for-age of the studied population is shown in Figure 2, which shows the curve is deviated from the median, skewed to the left and less flat in comparison to the WHO Z score reference population of the same age group. The mean Z-scores was $-1.61 \pm 1.30$, and the overall prevalence of stunting was $40.4 \%(95 \% \mathrm{CI}$; $29.8 \%-50.9 \%$ ). A variation on the prevalence of stunting between the two Districts was observed, whereas Dodoma Municipality had a prevalence of $26.3 \%$ (95\% CI; $23.2 \%$ $29.6 \%$ ) and that of Chamwino was $44.3 \%$ (95\% CI; 37.9\% - 50.9\%). Children of age between $12-23$ months were more stunted (82\%) compared to those of age $6-11$ months ( $p \leq 0.001)$. The stunting rate of boys was higher $46.9 \%(95 \% \mathrm{CI} ; 34.4 \%-59.5 \%)$ compared to that of girls $32.8 \%(95 \% \mathrm{CI} ; 19.7 \%$ - 45.8\%). Factors associated with stunting varied between the two Districts, variables such as birth weight, dietary diversity score, the age of introduction of complementary foods, sex of a child and maternal level of education as presented in Table 3. 

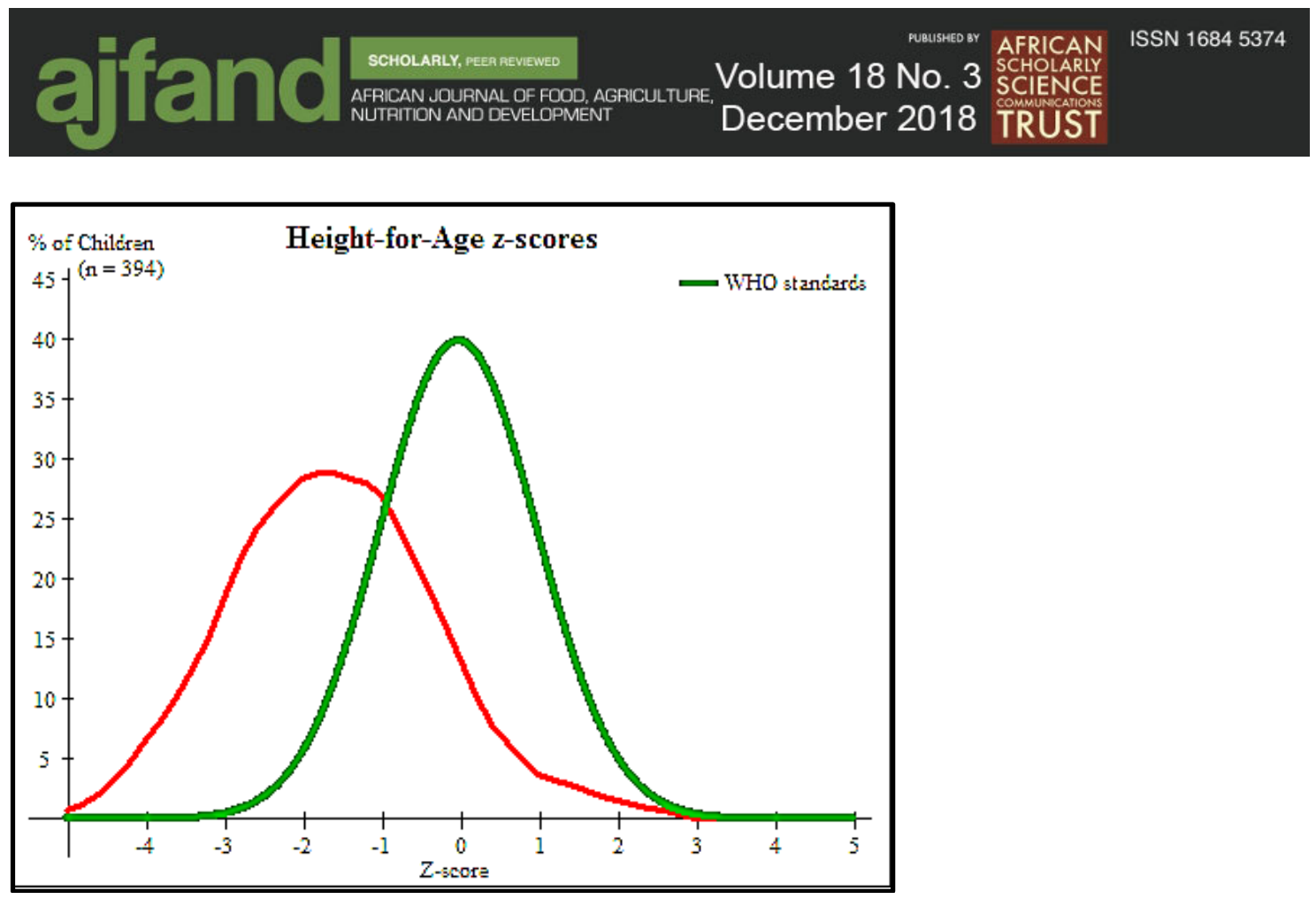

Figure 2: Distribution of height for age Z-scores compared to WHO growth standards in Chamwino and Dodoma Municipality

\section{Multivariate analysis for factors of stunting}

The multiple logistic regression analysis showed that factors that were statistically significant and independently associated with stunting were: age at which a child introduced to complementary foods $(\mathrm{AOR}=13.3,95 \% \mathrm{CI}, 2.6-67.6)$, maternal education $(\mathrm{AOR}=5.5,95 \% \mathrm{CI}, 1.0-9.8)$ and residence in Chamwino District $(\mathrm{AOR}=$ $3.2,95 \%, 1.3-5.9)$ as presented in Table 4.

\section{DISCUSSION}

The distribution of height-for-age Z-scores of the studied population deviated from that of the WHO reference population indicating undernutrition is prevalent among children in that the studied population failed to acquire normal height for age. Stunting prevalence was high (40.4\%) according to WHO national growth estimates [20]. The level of stunting reported in this study is similar to that reported in the Kilimanjaro region $(40.1 \%)[21,22]$. Stunting remains a significant public health concern in Dodoma region with a prevalence of $56 \%$ in $2010,45.2 \%$ in 2014 and $40.4 \%$ in 2015 as reported by the current study $[13,23]$. This shows a substantial decline of stunting rate, but also demonstrates a continuous failure to attain optimal growth due to increased risk of exposure associated with adverse health and nutritional conditions for a long time. Factors associated with stunting originate from diverse yet interrelated variables, some of which have been identified from this study as maternal education, the age of introduction of complementary foods and area of residence.

Multivariate regression analysis indicated that the odds of stunting were 13.3 times higher among children who were introduced to complementary food before the age of six months than those whose introduction was timely $(p=0.002)$. Time for the 
introduction of complementary foods is determined by several factors including ethnicity, geographical location, the social and economic situation [24]. The rate of early introduction of complementary foods was higher (67\%) in Chamwino District compared to Dodoma Municipality (48\%). This might be due to most of the mothers in rural areas spending much of their time on farms with less time to breastfeed. Introduction of complementary food before the recommended age of six months has been shown to be a contributing factor of poor growth rate in developing countries [25]. Most of the complementary foods given to infants are nutritionally inadequate in terms of micronutrients and protein content to meet the infant's physiological requirement, thus may predispose a child to the risk of growth faltering [26]. Early introduction to complementary foods reduces the volume of breast milk ingested by infants due to limited gastric capacity and predisposes infants to reduced protective benefits of breast milk [27]. However, poor hygienic practices during preparation and feeding of complementary foods, increases the risk of infant exposure to infection and diarrhea, also contributing to poor growth rate [28]. Islam et al. [29] observed that, $40 \%$ of complementary foods given to children were contaminated with coliform bacteria as a result of poor hygienic practices.

The present study has shown that the rate of child stunting was high in children under the care of uneducated mothers compared to those being cared for by educated mothers. Children whose mothers did not attend any formal education had a 5.5-fold higher odds of being stunted than those who attended primary education $(p=0.004)$. A mother is a primary care provider to child needs, but the type of care depends on literacy and awareness of the mother [30]. Maternal education has a greater influence on child nutritional status but also it depends on the level of education attained. However, high education levels have an impact on socio-economic status compared to low education levels [31,32]. Various factors are associated with maternal education and child nutritional status, these include utilization of health knowledge, small family size and increased income [33]. Literate mothers have improved knowledge related to health care utilization, child care and feeding practices which significantly affect a child's health and nutritional status. Abuya et al. [34] observed that low maternal education was a significant factor for chronic under nutrition of infant and young children. Negash et al. [35] observed a strong relationship between child nutritional status, mother's education and social economic status. Frost et al. [36] reported that the primary pathway connecting maternal education and child nutritional status is socio-economic status, though the utilization of health care information accounted for portions of the maternal education effect.

Variation of stunted growth to children between Dodoma Municipality and Chamwino Districts has been observed in this study. The prevalence of stunting was very high (44.3\%) in Chamwino District as compared to Dodoma Municipality (26.3\%). District of residence was significantly related to stunted growth, whereby children who resided in Chamwino District were more stunted (3.2 times) compared to those in Dodoma Municipality $(p=0.002)$. The differences in the prevalence of stunting between Chamwino District and Dodoma Municipality could be attributed to several factors including young age of the mother, early pregnancies, low maternal education, income differences, and cultural practices. Besides, households in Chamwino District reported 


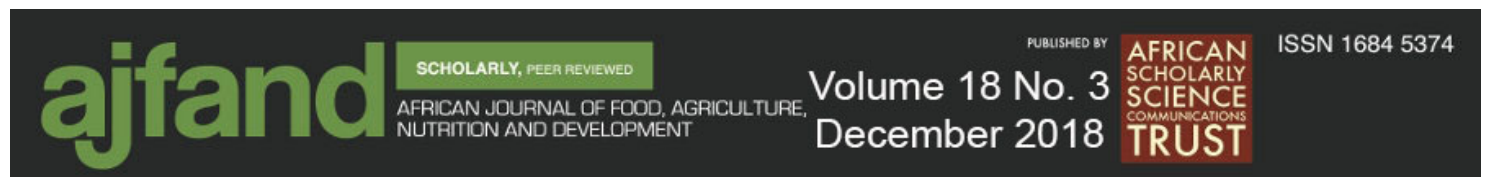

having inadequate food consumption as most could access only two meals per day. Other studies also reported similar observations that children residing in rural areas were more stunted than those in urban $[37,38]$.

Although there was no significant association between feeding frequency and stunting in multivariate analysis, the dietary pattern of the studied population was characterized by low DDS. About 48\% $(p=0.08)$ of household, consumed less than three food groups, hence the probability of attaining adequate nutrient intake was low due to a lack of dietary diversity. Cereals and vegetables were the food groups mostly consumed by the studied population. Food items such as meat, eggs, fruits, milk and milk products (except breast milk) were less consumed. These food items like eggs are usually sold at the market to generate household income. The current study found that very few children (18\%) reported consuming animal food source, this might be due to a low purchasing power that forced them to access other foods. The observation made in Mpwapwa District in Dodoma region found that only $6.7 \%$ of children consumed animal food source, the proportion is lower compared to the current study [39]. Under normal conditions, there is no single food offering all nutrients at a time except breast milk in the first six months. Thus, the more diverse the diet, the greater the opportunity of offering diverse nutrients in the same meal, hence increases the likelihood of attaining high dietary diversity scores. Taruvinga et al. [40] investigation reported that high dietary diversity score is likely to be attained by educated household and less likely to uneducated households. Dietary diversity is directly related to the quality of diet and inversely related to malnutrition in terms of inadequate nutrient supply and nutrient deficiencies [41].

Children aged $12-24$ months had a higher rate of stunting (82\%) than other age groups: $6-8$ months $(8.3 \%)$ and $9-11$ months $(9.7 \%)$. The risk of stunted growth increases as children approach their second year of life, growth often starts to decline at the age of 6 months and this continues up to 24 months. Deterioration of nutritional status after six months of age could be due to inappropriate timing of introduction to complementary foods or consumption of nutritionally inadequate complementary foods to infants which do not meet their nutritional requirements for growth. Growth shortfall begins at an early age under long-term exposure to associated factors of undernutrition and its adverse consequences being realized later. Nagahori et al. [42] also found a higher rate of stunting in older children $(p=0.0078)$. Additionally, TDHS (2015) found highest rate of stunting $33 \%$ and $43 \%$ to children aged $12-17$ and $18-23$ months respectively, as compared to children aged $9-11$ months who had the lowest proportion of $14.4 \%$ [10].

\section{CONCLUSION}

The study assessed the nutritional status of children aged 6 to 23 months and their predisposing factors to stunting in Dodoma Municipality and Chamwino District. The rate of stunted growth was high $(40.4 \%)$ according to WHO categorization criteria, Chamwino district had a higher prevalence of stunting (44.3\%) as compared to Dodoma Municipality (26.3\%). Identified factors associated with stunting in multivariate analysis in the current study were the early introduction of complementary foods, low maternal education level, and residing in Chamwino District. Generally, factors associated with 


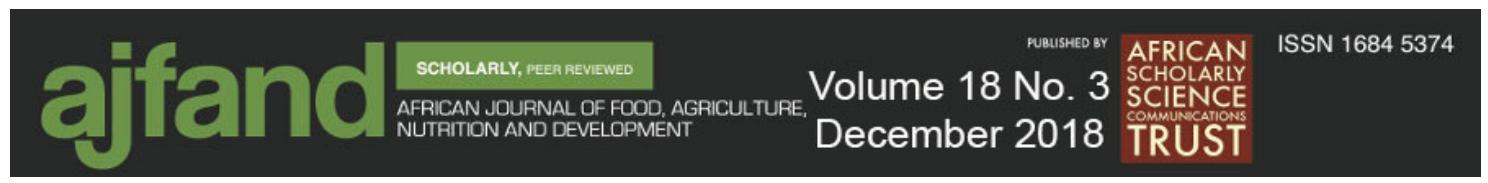

undernutrition are diverse and interrelated; this also includes food insecurity, diseases, health-seeking behavior and water, sanitation and hygiene practices. This implies that by increasing maternal education, adherence to the recommended time of introduction of complementary foods would reduce the rate of stunting. Therefore, the current findings serve to highlight the critical predisposing factors which may be prioritized for intervention by different actors.

\section{Limitation of the study}

The findings rely solely on the cross-sectional survey, which offers a snapshot of a single point in time.

\section{Authors' contributions}

NM: designed the study, collected and analyzed the data and wrote the manuscript. NK, $\mathrm{JK}$, AM, designed, supervised the study, reviewed and approved the manuscript to be published.

\section{Acknowledgement}

The authors acknowledge funding from the Government of Tanzania through Nelson Mandela African Institution of Science and Technology (NM-AIST) Arusha, Tanzania.

\section{Competing Interest}

The authors declare that there is no competing interest. 


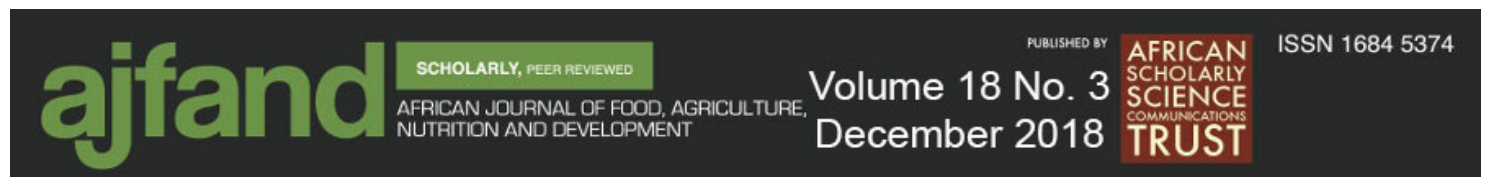

Table 1: Social Demographic information

\begin{tabular}{|c|c|c|c|}
\hline Variable & $\begin{array}{l}\text { Dodoma } \\
\text { Municipality }\end{array}$ & Chamwino & Total \\
\hline Children, N = 394 & $\begin{array}{l}n=175 \\
(\%)\end{array}$ & $\begin{array}{l}n=219 \\
(\%)\end{array}$ & $\begin{array}{l}\mathrm{n}=\mathbf{3 9 4} \\
(\%)\end{array}$ \\
\hline $\begin{array}{l}\text { Sex of the child } \\
\text { Male } \\
\text { Female }\end{array}$ & $\begin{array}{l}53.1 \\
46.9\end{array}$ & $\begin{array}{l}50.7 \\
49.3\end{array}$ & $\begin{array}{l}51.8 \\
48.2\end{array}$ \\
\hline $\begin{array}{l}\text { Age of the child } \\
6-11 \text { months } \\
12-23 \text { months }\end{array}$ & $\begin{array}{l}44.6 \\
55.4\end{array}$ & $\begin{array}{l}35.2 \\
64.8\end{array}$ & $\begin{array}{l}39.9 \\
60.7\end{array}$ \\
\hline $\begin{array}{l}\text { Mothers/care takers, } \mathbf{N}=\mathbf{3 9 4} \\
\text { Age of the mother } \\
14-25 \text { years } \\
>25 \text { years }\end{array}$ & $\begin{array}{l}\mathbf{n}=\mathbf{1 7 5} \\
44.0 \\
56.0\end{array}$ & $\begin{array}{l}\mathbf{n}=\mathbf{2 1 9} \\
41.6 \\
58.4\end{array}$ & $\begin{array}{l}\mathbf{n}=\mathbf{3 9 4} \\
42.6 \\
57.4\end{array}$ \\
\hline $\begin{array}{l}\text { Education level } \\
\text { None } \\
\text { Primary education } \\
\text { Secondary and above }\end{array}$ & $\begin{array}{l}34.9 \\
52.6 \\
12.5\end{array}$ & $\begin{array}{l}28.8 \\
65.3 \\
5.9\end{array}$ & $\begin{array}{l}31.5 \\
59.6 \\
8.9\end{array}$ \\
\hline $\begin{array}{l}\text { Occupation } \\
\text { Employed } \\
\text { Agriculture } \\
\text { Livestock keeping } \\
\text { Business }\end{array}$ & $\begin{array}{l}6.3 \\
66.3 \\
0.6 \\
26.8\end{array}$ & $\begin{array}{l}3.7 \\
89 \\
0.9 \\
6.4\end{array}$ & $\begin{array}{l}4.8 \\
78.9 \\
0.8 \\
15.5\end{array}$ \\
\hline $\begin{array}{l}\text { Marital status } \\
\text { Married } \\
\text { Single } \\
\text { Divorced } \\
\text { Widow }\end{array}$ & $\begin{array}{l}85.1 \\
8 \\
4 \\
2.9\end{array}$ & $\begin{array}{l}93.2 \\
5.9 \\
0 \\
0.9 \\
\end{array}$ & $\begin{array}{l}89.6 \\
6.9 \\
1.7 \\
1.8 \\
\end{array}$ \\
\hline
\end{tabular}




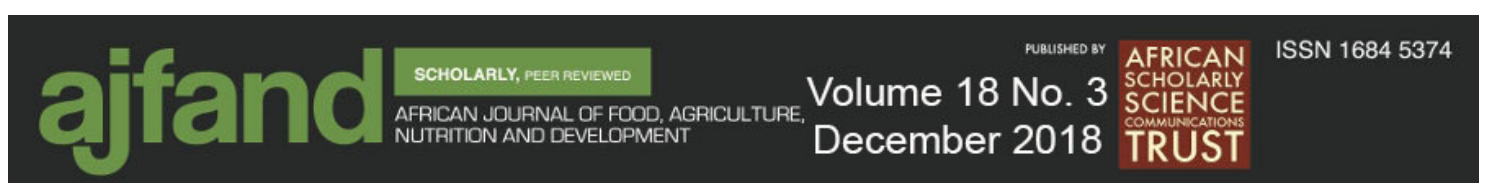

Table 2: Consumption of different types of food groups by children

Food group

DDS: \% of children

consuming each food group

Cereals based foods

100

Roots and tubers (banana, potatoes, cassava)

18.1

Legumes

29.4

Fruits

7.1

Vegetables

57.9

Meat and meat product

18

Fish

8.9

Eggs

Milk

11

Oil and fats

72

Sugars

49

Others (Spices and Condiments)

29.4 


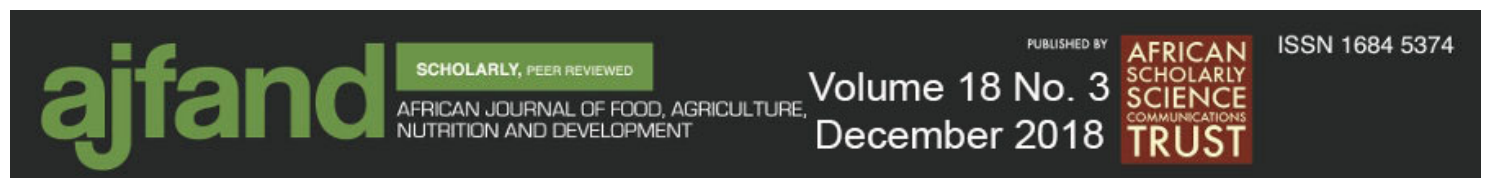

Table 3: Factors associated with stunting in Dodoma Municipality and Chamwino District

\begin{tabular}{|c|c|c|c|c|c|c|c|}
\hline \multirow[b]{2}{*}{ Variable } & \multicolumn{4}{|c|}{ Dodoma Municipality } & \multicolumn{3}{|c|}{ Chamwino District } \\
\hline & $\%$ stun & $\overline{C O R}(95 \% \mathrm{CI})$ & & AOR(95\%CI) & $\%$ stun & COR(95\%CI) & AOR(95\%CI) \\
\hline Children N=394 & $n=175$ & & & & $\mathrm{n}=\mathbf{2 1 9}$ & & \\
\hline \multicolumn{8}{|l|}{ DDS** } \\
\hline low & 41.9 & $1.4(0.7-2.8)$ & & $0.4(0.01-0.2)$ & 34.5 & $3.3(1.9-5.7)^{*}$ & $0.1(0.02-0.2)$ \\
\hline Medium & 17.4 & & 1 & & 17.4 & & \\
\hline \multicolumn{8}{|l|}{ Birth weight } \\
\hline$<2.5$ & 23.4 & $1.4(0.6-3.2)$ & & $0.1(0.01-0.5)$ & 4.6 & $3.5(1.6-7.8)^{*}$ & $0.1(0.01-0.9)$ \\
\hline$>2.6$ & 20.0 & & 1 & & 34.2 & & \\
\hline \multicolumn{8}{|l|}{ Age of a child } \\
\hline $6-11$ months & 14 & & 1 & & 32.6 & & \\
\hline 12- 23 months & 86 & $0.1(0.0-0.2)^{*}$ & & $0.4(0.2(0.9)$ & 67.4 & $0.5(0.3-1)^{*}$ & $1.3(0.6-2.8)$ \\
\hline \multicolumn{8}{|l|}{ Feeding practices } \\
\hline Below & 68.6 & $0.9(0.2-3.6)$ & & $1.3(0.7-2.4)$ & 49.8 & $0.9(0.3-2.4)$ & $0.3(0.1-0.5)$ \\
\hline Normal & 24.6 & & 1 & & 41.1 & & \\
\hline \multicolumn{8}{|c|}{ Age of 1ntroduction of CF } \\
\hline $1-5$ months & 41.7 & $5.3(2.1-14.5)^{*}$ & & $0.2(0.1-0.5)$ & 40.6 & $0.02(0.01-0.05)^{3}$ & $0.2(0.1-0.5)$ \\
\hline$>6$ months & 32.0 & & 1 & & 14.2 & & \\
\hline \multicolumn{8}{|l|}{ Sex of a child } \\
\hline Male & 63 & $1.7(0.8-3.4)$ & & $18.1(6.0-54.2)$ & 58.6 & $0.5(0.3-0.9)^{*}$ & $20.3(6.8-60.5)$ \\
\hline Female & 37 & & 1 & & 41.4 & & \\
\hline Mother N=394 & $n=175$ & & & & $\mathbf{n}=\mathbf{2 1 9}$ & & \\
\hline \multicolumn{8}{|l|}{ Age of the mother } \\
\hline$<25$ years & 33.1 & $0.8(0.4-1.7)$ & & $9.4(3.5-24.8)$ & 22.4 & $0.9(0.5-1.6)$ & $1(0.6-1.8)$ \\
\hline$>26$ years & 40.6 & & 1 & & 32.4 & & \\
\hline \multicolumn{8}{|c|}{ Maternal level of education } \\
\hline No formal & 62.8 & $0.01(0.0-0.4)^{*}$ & & $0.1(0.03-0.4)$ & 50.9 & $0.004(0.00-0.01)^{*}$ & $0.2(0.1-0.5)$ \\
\hline Primary education & 7.7 & & 1 & & 2.8 & & \\
\hline \multicolumn{8}{|l|}{ Source of income } \\
\hline Agriculture & 50.3 & $0.7(0.4-1.5)$ & & $18.1(7.15-35.9)$ & 47.5 & $1.7(0.7-4.3)$ & $0.01(0.00-0.03)$ \\
\hline Non agriculture & 10.3 & & 1 & & 3.7 & & \\
\hline
\end{tabular}

${ }^{*}$ Significance at $p \leq 0.05$, Stun $=$ Stunting, $C F=$ Complementary food, $* *$ Some information (with extremity) were excluded 


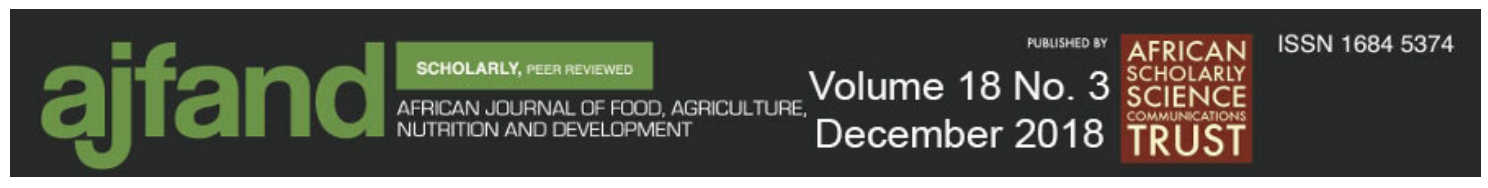

Table 4: Multivariate logistic regression of factors of stunting, $N=394$

\begin{tabular}{|c|c|c|c|c|}
\hline Variable & $\mathbf{N}$ & $\%$ stun & $\operatorname{COR}(95 \% \mathrm{CI})$ & $\operatorname{AOR}(95 \% C I)$ \\
\hline \multicolumn{5}{|l|}{ DDS** } \\
\hline Low & 180 & 43.8 & $1.9(1.3-2.8)$ & $0.6(0.2-1.3)$ \\
\hline Medium & 210 & 56.2 & 1 & \\
\hline \multicolumn{5}{|c|}{ Maternal level of education** } \\
\hline No formal & 153 & 93.1 & $0.006(0.003-0.01)$ & $5.5(1.0-9.8)^{*}$ \\
\hline Primary education & 217 & 6.9 & 1 & \\
\hline \multicolumn{5}{|l|}{ Age of a child } \\
\hline $6-11$ months & 155 & 20 & 1 & \\
\hline $12-23$ months & 239 & 80 & $0.24(0.2-0.4)$ & $0.2(0.06-1.2)$ \\
\hline \multicolumn{5}{|c|}{ Age of 1 ntroduction of $\mathrm{CF}$} \\
\hline $1-5$ months & 226 & 95.9 & $0.02(0.01-0.06)$ & $13.3(2.6-67.7)^{*}$ \\
\hline$>6$ months & 168 & 4.1 & 1 & \\
\hline \multicolumn{5}{|l|}{ District } \\
\hline Chamwino & 219 & 68.3 & $2.3(1.5-3.5)$ & $3.2(1.3-5.9)^{*}$ \\
\hline Dodoma Municipality & 175 & 31.7 & 1 & \\
\hline \multicolumn{5}{|l|}{ Occupation } \\
\hline Agriculture & 311 & 48.7 & $1.3(0.8-2.3)$ & $0.4(0.1-1.9)$ \\
\hline Non agriculture & 83 & 6.6 & 1 & \\
\hline \multicolumn{5}{|l|}{ Feeding frequency } \\
\hline Below & 362 & 58.1 & $0.9(0.4-2.0)$ & $0.6(0.3-1.5)$ \\
\hline Normal & 32 & 3 & 1 & \\
\hline
\end{tabular}




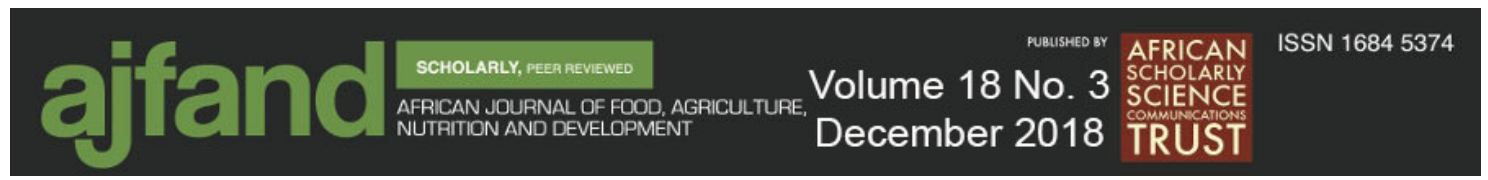

\section{REFERENCES}

1. Bhutta ZA and RA Salam Global Nutrition Epidemiology and Trends. Ann Nutr Metab 2012;61:19-27.

2. Black RE, Victora CG, Walker SP, Bhutta ZA, Christian P, de Onis M, Ezzati M, Grantham-McGregor S, Katz J, Martorell R and R Uauy Maternal and child undernutrition and overweight in low-income and middle-income countries. Lancet 2013;382:427-51.

3. Collins S Treating severe acute malnutrition seriously. Arch. Dis. Child 2007;92:453-61.

4. Dewey KKG The Challenge of Meeting Nutrient Needs of Infants and Young Children during the Period of Complementary Feeding: An Evolutionary Perspective. J Nutr 2013;143:2050-4.

5. Prendergast AJ and JH Humphrey The stunting syndrome in developing countries. Paediatr. Int. Child Health 2014;34:250-65.

6. Grantham-McGregor S, Cheung YB, Cueto S, Glewwe P, Richter L and B Strupp Developmental potential in the first 5 years for children in developing countries. Lancet. 2007;369:60-70.

7. Casale D, Desmond $\mathbf{C}$ and $\mathbf{L}$ Richter The association between stunting and psychosocial development among preschool children: A study using the South African Birth to Twenty cohort data. Child Care Health Dev 2014;40:900-10.

8. Sokolovic N, Selvam S, Srinivasan K, Thankachan P, Kurpad AV and T Thomas Catch-up growth does not associate with cognitive development in Indian school-age children. European Journal of Clinical Nutrition 2014;68:14-8.

9. Walker SP, Chang SM, Wright A, Osmond C and SM Grantham-McGregor Early childhood stunting is associated with lower developmental levels in the subsequent generation of children. Journal of Nutrition 2015;145:823-8.

10. Sudfeld CR, Charles McCoy D, Danaei G, Fink G, Ezzati M, Andrews KG and WW Fawzi Linear Growth and Child Development in Low- and MiddleIncome Countries: A Meta-Analysis. Pediatrics 2015;135:e1266-75.

11. National Bureau of Statistics. Tanzania Demographic and Health Survey and Malaria Indicator Survey 2015 - 2016. Tanzania Demogr. Heal. Surv. Malar. Indic. 2016.

12. National Bureau of Statistics (NBS). Tanzania Demographic and Health Survey 1996. 1997.

13. National Bureau of Statistics, Macro International Inc. Tanzania Reproductive and Child Health Survey 1999. Statistics (Ber). 2000. 


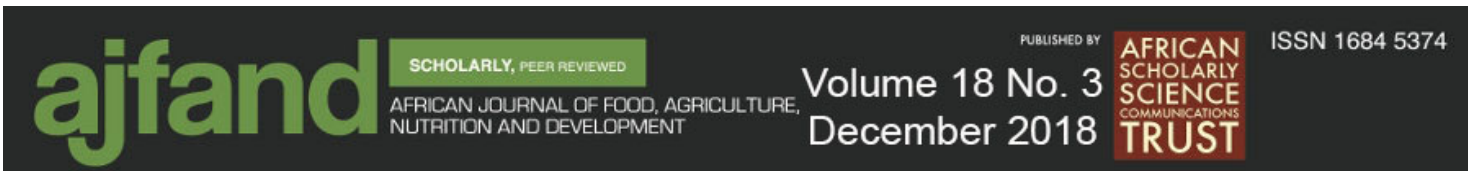

14. National Bureau of Statistics (NBS). Tanzania Demographic and Health Survey 2010. Tanzania Demogr. Heal. Surv. 2011.

15. Black RE, Allen LH, Bhutta ZA, Caulfield LE, de Onis M and M Ezzati Maternal and child undernutrition: global and regional exposures and health consequences. Lancet. 2008;371:243-60.

16. Fekadu Y, Mesfin A, Haile D and BJ Stoecker Factors associated with nutritional status of infants and young children in Somali Region, Ethiopia : a cross- sectional study. BMC Public Health 2015;1-9.

17. Varkevisser CM, Pathmanathan I and A Brownlee Designing and conducting health syatems research projects (Vol. 16). Geneva, Switzerland. 1991; retrieved from http://www.who.int/iris/handle/10665/37051.

18. Food and Agriculture Organization Guidelines for measuring household and individual dietary diversity. 2008.

19. WHO. Physical status: the use and interpretation of anthropometry. Report of a WHO Expert Committee. World Health Organ. Tech. Rep. Ser. 1995. p. 1-452.

20. Schwarz NG, Grobusch MP, Decker M-L, Goesch J, Poetschke M, Oyakhirome S, Kombila D, Fortin J, Lell B, Issifou S, Kremsner PG and K Klipstein-Grobusch WHO 2006 child growth standards: implications for the prevalence of stunting and underweight-for-age in a birth cohort of Gabonese children in comparison to the Centers for Disease Control and Prevention 2000 growth charts and the National Center for Heal. Public Health Nutrition 2008;11:714-9.

21. Abubakar A, Uriyo J, Msuya SE and M Swai Prevalence and Risk Factors for Poor Nutritional Status among Children in the Kilimanjaro Region of Tanzania. Int. J. Environ. Res. Public Health 2012;9:3506-18.

22. Asfaw M, Wondaferash M, Taha $M$ and $\mathbf{L}$ Dube Prevalence of undernutrition and associated factors among children aged between six to fifty nine months in Bule Hora district, South Ethiopia. BMC Public Health 2015;15:41.

23. Welfare S Ministry of Health and Social Welfare National Nutrition Strategy. 2015.

24. Muhimbula HS and A Issa-zacharia Persistent child malnutrition in Tanzania : Risks associated with traditional complementary foods ( A review ). African Journal of Food Science 2010;4:679-92.

25. Patel A, Pusdekar Y, Badhoniya N, Borkar J, Agho KE and MJ Dibley Determinants of inappropriate complementary feeding practices in young children in India: secondary analysis of National Family Health Survey 2005-2006. Matern. Child Nutrition 2012;8:28-44. 


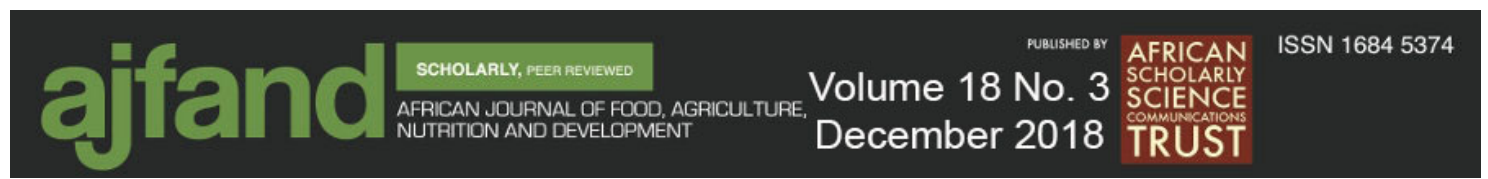

26. Anigo KM, Ameh D a, Ibrahim S and SS Danbauchi Nutrient composition of commonly used complementary foods in North western Nigeria. African Journal of Biotechnolpgy 2009;8:4211-6.

27. Tang L, Lee $\mathbf{A H}$ and $\mathbf{C W}$ Binns Predictors of early introduction of complementary feeding: Longitudinal study. Pediatrics International 2015;57:126-30.

28. Romulus-Nieuwelink JJC, Doak C, Albernaz E, Victora CG and H Haisma Breast milk and complementary food intake in Brazilian infants according to socioeconomic position. Int. J. Pediatr. Obes 2011;6:e508-14.

29. Islam MA, Ahmed T, Faruque ASG, Rahman S, Das SK, Ahmed D, Fattori V, Clarke R, Endtz HP and A Craviato Microbiological quality of complementary foods and its association with diarrhoeal morbidity and nutritional status of Bangladeshi children. European Journal of Clinical Nutrition 2012;66:1242-6.

30. Bbaale $\mathbf{E}$ Maternal education and child nutritional status: evidence from Uganda. African Journal of Economi and Management Studies 2014;5:52-74.

31. Ali S, Chaudry T and Q Naqvi Effect of maternal literacy on child health: Myth or reality. Ann. Pak. Inst. Med. Sci 2011;7:100-3.

32. Chen $\mathbf{Y}$ and $\mathbf{H}$ Li Mother's education and child health: Is there a nurturing effect? Journal of Health Economics 2009;28:413-26.

33. Anwar S, Nasreen $\mathbf{S}$, Batool $\mathbf{Z}$ and $\mathbf{Z}$ Husain Maternal education and child nutritional status in Bangladesh: Evidence from demographic and health survey data. Pakistan J. Life Soc. Sci. 2013;11:77-84.

34. Abuya BA, Ciera J and E Kimani-Murage Effect of mother's education on child's nutritional status in the slums of Nairobi. BMC Pediatrics 2012;12:80.

35. Negash C, Whiting SJ, Henry CJ, Belachew $\mathbf{T}$ and TG Hailemariam Association between maternal and child nutritional status in Hula, rural Southern Ethiopia: A cross sectional study. PLoS One 2015;10:1-8.

36. Frost MB, Forste $\mathbf{R}$ and $\mathbf{D W}$ Haas Maternal education and child nutritional status in Bolivia: Finding the links. Soc. Sci. Med 2005;60:395-407.

37. Amare Zelellw D Prevalence and Associated Factors of Stunting Among Schoolchildren, in Debre Markos Town and Gozamen Woreda, East Gojjam Zone, Amhara Regional State, Ethiopia, 2013. Journal of Nutrition and Food Sciences 2011;S8:007:1-5. 


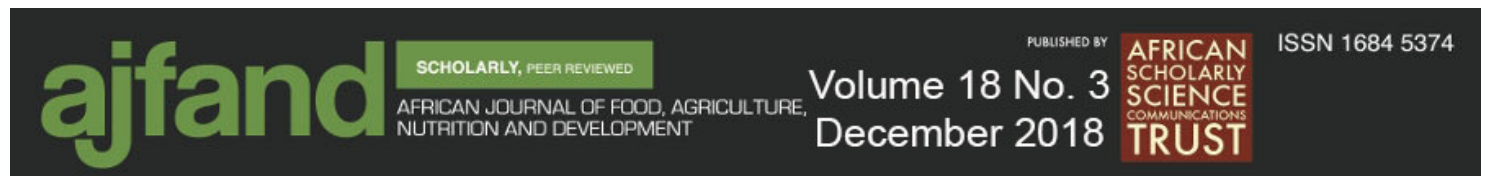

38. Nouri Saeidlou S, Babaei F and $\mathbf{P}$ Ayremlou Malnutrition, overweight, and obesity among urban and rural children in north of west azerbijan. Iran. J. Obes 2014;2014:1-6.

39. Kulwa KBM, Mamiro PS, Kimanya ME, Mziray R and PW Kolsteren Feeding practices and nutrient content of complementary meals in rural central Tanzania: implications for dietary adequacy and nutritional status. BMC Pediatric 2015;15:171.

40. Taruvinga A, Muchenje V and A Mushunje Determinants of rural household dietary diversity: The case of Amatole and Nyandeni districts, South Africa. International Journal of Development andSustaunability 2013;2:4:1 - 15.

41. Labadarios D, Steyn NP and J Nel How diverse is the diet of adult South Africans? Nutrition Journal 2011;10:33.

42. Nagahori C, Tchuani JP and T Yamauchi Factors associated with nutritional status in children aged 5-24 months in the Republic of Cameroon. Nursinng nad Health Sciences 2015;17:229-35. 